\title{
Roger B. McDonald: Biology of aging
}

\author{
Garland Science, Taylor and Franics Group LLC, 2014, 368 pp, price 42GBP \\ (paper back), ISBN 978-0-8153-4213-7
}

\author{
Suresh I. S. Rattan
}

Received: 20 December 2013/Accepted: 24 December 2013/Published online: 19 January 2014

(C) Springer Science+Business Media Dordrecht 2014

If you are teaching or you intend to teach an undergraduate or even a graduate course on biogerontology, then this is the one to use as the text book. Unlike numerous multi-author compilations on various aspects of ageing, this single author book is perhaps the best one to come out with a great potential for becoming a highly useful and popular book.

Roger McDonald, a Professor of Nutrition, at the University of California at Davis, has done an excellent and admirable job of creating this book which gives an introductory, yet comprehensive, tour of the fascinating and challenging subject of the biology of ageing. The book is organised in 10 chapters and develops various aspects of biogerontology from the basic concepts, such as the definitions of ageing and measuring biological ageing to the evolutionary theories of ageing and longevity, ageing of cells in and outside the body, genetics and molecular biology of ageing, ageing in plants, human longevity and the physiology of human ageing, age-related diseases in various systems, and finally the possibilities or impossibility of ageing interventions. One can, of course, disagree or feel disappointed with some of the interpretations or the choices made by the author in including or excluding some ideas and terms (for example, not even once using the term and concept of hormesis-one of my present favourites!), it does not undermine the importance and usefulness of this text book.

Each chapter is well organised giving first a brief background to the basic biology behind the topic before getting into its ageing aspects. The text is highly readable and the use of drawings and pictures is extensive and appropriate. Most usefully, each chapter ends with a reminder list of essential concepts covered in that chapter, followed by about 10 discussion questions around that topic, which can be the basis of thinking, rethinking and arguing about the topic. Each chapter also provides a list of articles, mostly the review articles, for further reading and discussion. Additionally, the book provides access to online resources from the publisher's website, which are highly useful for students and teachers alike. It is a really well worked book, and I recommend it highly for its value as an introductory text book in biogerontology.
S. I. S. Rattan ( $\square)$

Laboratory of Cellular Ageing, Department of Molecular Biology and Genetics, Aarhus University, 8000 Århus, Denmark

e-mail: rattan@mb.au.dk 